\title{
Universiteit
}

Leiden

The Netherlands

\section{Neonatal transfusion practices}

Lindern, J.S. von

\section{Citation}

Lindern, J. S. von. (2011, October 27). Neonatal transfusion practices.

Retrieved from https://hdl.handle.net/1887/17989

Version: $\quad$ Corrected Publisher's Version

Licence agreement concerning inclusion of doctoral

License: $\quad$ thesis in the Institutional Repository of the University of Leiden

Downloaded from: https://hdl.handle.net/1887/17989

Note: To cite this publication please use the final published version (if applicable). 
Chapter 2 


\section{The use of blood products in perinatal medicine}

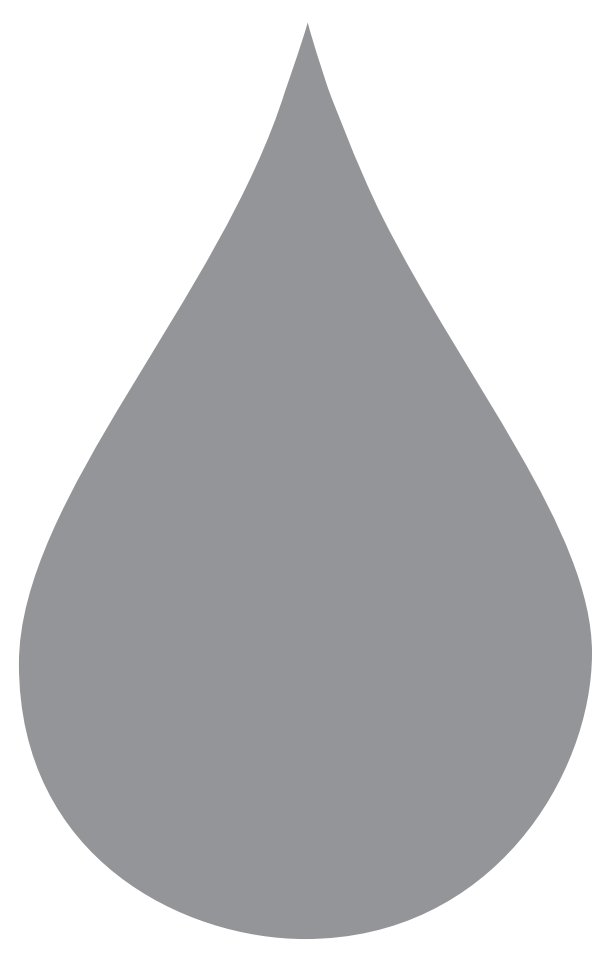

Jeannette S. von Lindern, Anneke Brand

Seminars in Fetal \& Neonatal Medicine 2008; 13:272-281 


\section{Summary}

Fetal and neonatal medicine is a field with many new procedures and techniques. An increasing number of centres worldwide give intrauterine transfusions, which is considered to be standard-of-care treatment for severe fetal anaemia. The survival of very prematurely born neonates, in particular of a gestational age of $<28$ weeks, has greatly improved the last decade but almost all these children need transfusions. Although in many cases such blood transfusions are life saving, randomized controlled studies investigating appropriate indications, transfusion volume and type of blood product, have not been performed. Most of the protocols used are expert based. 


\section{Introduction}

Fetal and neonatal medicine is a field with many new procedures and techniques. In many fetal and neonatal conditions, transfusions of blood products are life saving. However, randomized controlled studies into the appropriate indications, transfusion volume or type of blood product are needed. Studies on red-cell transfusions in adult patients reveal that, depending on the indication, too few or too many transfusions are associated with a worse outcome. Moreover, the efficacy of platelet transfusion triggers is currently under question, as the prevention of bleeding is scarcely demonstrated. There is no reason to assume that this should not apply to fetuses and newborns. Currently most of the protocols used with fetuses and newborns are expert based.

This paper presents an overview of the literature, transfusion guidelines and recommendations for further research for the most common transfusion indications.

\section{Intrauterine transfusion}

Ultrasound-guided umbilical cord puncture and transfusion is possible after the $17^{\text {th }}$ week of gestation. In experienced centres, morbidity and mortality is 1-2\% per procedure, ${ }^{1}$ although the complication rate is higher if the gestational age is $<20$ weeks or the fetus has thrombocytopenia ..$^{1,2}$ The major indication for treatment by intrauterine transfusion (IUT) is anaemia caused by maternal antibodies. Other, more rare, indications for fetal blood transfusion include human parvovirus B19 infection, severe fetomaternal haemorrhage, twin-twin transfusion syndrome and homozygous $\alpha$-thalassemia. The decision to treat fetal thrombocytopenia with intrauterine platelet transfusions (IUPT) must be balanced against the risk of the procedure.

\section{Transfusions of red blood cells}

Haemolytic disease of the newborn (HDN) due to maternal immunoglobulin G (IgG) antibodies directed against an incompatible paternal antigen expressed on the child's erythrocytes is a major cause of in-utero anaemia. Active maternal IgG transport takes place from the 12th gestational week and, at birth, the IgG levels in the child are higher than in the mother. The severity of HDN depends on the haemolytic potential of the antibodies, which is determined by the expression of the antigen on mature fetal/neonatal red cells or on erythroid precursor cells.

Major ABO incompatibility occurs in 20-25\% of pregnancies, often affecting the first-born child. Anaemia is rare because $A B O$ antigens are not fully expressed at birth. HDN due to 
anti-Rh-D or other red-cell antibodies generally presents with clinical symptoms in the second or later pregnancies and tends, unlike $A B O$ antagonism, to be aggravated in the next child.

In Caucasian populations, severe HDN is caused predominantly by Rh-D, followed by anti-K1 and anti-c antibodies. Incidentally, antibodies against very rare (private) antigens or against antigens present in the majority of the population (public) cause HDN. ${ }^{1}$

When clinically relevant antibodies are identified, pregnancy management by an experienced team is warranted. This includes non-invasive estimation of the degree of anaemia by ultrasound flow measurement of the peak systolic velocity of the middle cerebral artery. It is important to start IUT before hydrops has developed, as survival decreases from $95 \%$ to $<70 \%$ in cases of severe, irreversible hydrops. ${ }^{1}$ As deduced from small series, IUT is also beneficial for hydrops arising from parvovirus B19 infection. ${ }^{3}$

If possible, fetal red cells obtained by the first umbilical puncture should be extensively typed, because after the second transfusion the fetal erythropoiesis is often completely depressed. Red cells used for IUT should fulfil the same testing criteria for transmittable infectious diseases as standard transfusions. In addition, guidelines recommend the following criteria for the product used:4-6

- blood groups are compatible with maternal antibodies

- it does not transmit cytomegalovirus (CMV) or - preferentially - parvovirus B19

- there is a long erythrocyte survival

- it does not cause transfusion-associated graft versus host disease

- it is devoid of substances that might be toxic for the fetus

- it has a haematocrit $(\mathrm{Ht})$ that is as high as viscosity allows

- it is of a temperature that is sufficient to avoid cold exposure

To fulfil these criteria, the unit of blood used for IUT is generally O, Rh-DCE negative (unless anti-c), Kell negative and, if applicable, compatible with other maternal antibodies. The unit must be free of clinically significant red-cell antibodies. ${ }^{5} \mathrm{~A}$ compatibility test with new maternal serum is necessary because approximately $25 \%$ of woman receiving IUT develop additional red-cell antibodies, particularly after transplacental puncture. ${ }^{7,8}$ Leucocytes must be removed by filtration to prevent CMV transmission, although many centres additionally select CMV-seronegative donors, ${ }^{5}$ and some also use parvovirus-B19-safe blood. ${ }^{4}$ The red cells used for IUT are generally stored for less than 3-5 days to offer a long erythrocyte survival. ${ }^{4-6}$ To prevent transfusion-associated graft versus host disease (TA-GVHD), the red cells are irradiated with $25 \mathrm{~Gy}{ }^{4-6}$ Because the transfused volume is huge (in relation to the fetoplacental blood volume), the transfusion speed is fast (often accomplished within 30 
$\mathrm{min}$ ) and the intrahepatic or intracardiac transfusion route may be used, much attention has been paid to the level of potassium and to the blood temperature as possible causes of fetal bradycardia and cardiac arrest. ${ }^{9,10}$ Both irradiation and the packing of red cells by centrifugation to obtain a haematocrit of $80 \pm 5 \%$ enhance hyperkalemia. Galligan and colleagues compared washing (to remove adenine and potassium) in three different solutes: Ringers' lactate, $\mathrm{NaCl} 0.9 \%$ and plasma. ${ }^{10}$ Although plasma washing resulted in the lowest potassium levels, after washing of 3-5-day-old red cells with $\mathrm{NaCl} 0.9 \%$ and subsequent storage for up to $4 \mathrm{~h}$, the potassium level remained below $12 \mathrm{mmol} / \mathrm{L}$, which was considered safe for IUT. This emphasizes the importance of limiting the number of centrifugations and of aiming for a short interval between blood processing/irradiation and transfusion, although the allowed ranges mentioned in guidelines vary by up to $24 \mathrm{~h} .^{5}$

An alternative source of erythrocytes for IUT, and an inevitable source in case of HDN due to an antipublic antibody, are washed maternal red cells. Even major ABO-mismatched cells have been used. Healthy females, supplemented with iron, folate and vitamins can donate up to six units during pregnancy. ${ }^{11} \mathrm{~A}$ theoretical advantage is an estimated $50 \%$ reduction of maternal new antibody formation. ${ }^{8}$ One study compared maternal and donor transfusions for IUT and observed, towards the end of pregnancy and in the neonatal period, a reduced transfusion requirement after maternal blood. This was attributed to increased reticulocytosis after repeated blood donation. ${ }^{12}$

Many centres perform a combination of intravascular and intraperitoneal transfusions; the latter are less effective in case of hydrops. IUT aims to bring the post-transfusion $\mathrm{Ht}$ to $45 \%$ (or lower in severely anaemic hydropic fetuses) and several formulae made by the pioneers in this field are still in use. ${ }^{13,14}$ After the first IUT, a second transfusion is generally needed after 1-2 weeks. Subsequent IUTs require a 3-4 week interval, as there is a 1-2\% daily decay of transfused red cells. IUT exerts several acute vascular dynamic effects related to changes in blood volume, viscosity, $\mathrm{pH}$ and 2,3-biphosphoglycerate-related oxygen delivery. There is often a transient decrease in cardiac output. Immediately after IUT, platelets decrease by more than $50 \%$ because of haemodilution and - possibly by induction of stress factors and demargination - numbers of monocytes and granulocytes increase relative to platelets. ${ }^{15}$ Iron overload is a long-term effect of both haemolysis and transfusion. It can play a role in neonatal cholestasis and hepatitis. ${ }^{16}$ In Rh-D HDN associated with hydrops, there is a $10-30 \%$ risk of concomitant thrombocytopenia below $50 \times 10^{9} / \mathrm{L}$ and it is recommended to have platelets available for transfusion when umbilical vascular puncture is performed in hydropic children. ${ }^{17,18}$ 


\section{Intrauterine platelet transfusion}

In contrast to the existing consensus for IUT in fetal anaemia, the practice of IUPT for fetal thrombocytopenia is more controversial. Most threatening thrombocytopenia occurs in fetal/neonatal alloimmune thrombocytopenia (FNAITP). In Caucasian populations, maternal anti-human platelet antigen (HPA)-1a is the dominant cause, followed by anti-5b-antibodies. ${ }^{19}$ In 15-20\% of FNAITP cases, non-HPA-1a/non-HPA-5b antibodies are present or antibodies cannot be detected..$^{20}$ Thirty percent of women possess anti-HLA class I antibodies at delivery, which can be detected in cord blood, but there is no clear relationship between the presence of HLA antibodies and neonatal thrombocytopenia. ${ }^{21}$

The indication for IUPT is prevention of severe in-utero bleeding. From a prospective study in the UK, it was estimated that anti-HPA-1a antibodies caused intracranial haemorrhage (ICH) in 1 out of 12.000-25.000 pregnancies; the majority occurring in-utero between 30 and 35 weeks of gestation and in $50 \%$ affecting the firstborn. ${ }^{22}$

Bussel et al. were the first to report that weekly maternal high-dose intravenous immunoglobulin (IVIG, $1.0 \mathrm{~g} / \mathrm{kg}$ maternal weight) was effective at elevating the fetal platelet count and preventing ICH. ${ }^{23}$ IVIG is now first-line treatment of FNAITP in subsequent pregnancies, eventually adjusted with corticosteroids and IUPT. The management of FNAITP is based on the history of the previous affected child. After the birth of a child with $\mathrm{ICH}$, the risk for $\mathrm{ICH}$ in the next pregnancy for a child carrying the offending antigen is approximately $80 \% .{ }^{24}$ Although this high recurrence rate clearly requires intervention, we have found that the high rate of procedure-related fetal complications and the boosting of antiplatelet antibodies by IUPT has gradually resulted in less invasive treatment in our centre. ${ }^{25}$

In case of a posterior cord insertion, IUPT has an increased risk. Withholding invasive treatment should be considered. In 60\%-75\% of cases, maternal IVIG results in improvement of the fetal platelet count. Moreover, even if the platelet count remains low, IVIG can protect against ICH. ${ }^{21,25}$ In cases of a previous child with thrombocytopenia but without $\mathrm{ICH}$, the complication rate of IUPT and the need to repeat transfusions every 7-10 days outweighs the $7-13 \%$ risk of $\mathrm{ICH}$ in the next child. ${ }^{24,26}$

In maternal autoimmune thrombocytopenia there is virtually no indication for IUPT because in-utero ICH has not been reported. ${ }^{27}$ In hydropic foetuses with severe Rh-D HDN or parvovirus B19 infection, occurrence of severe intrauterine bleeding or $\mathrm{ICH}$ is rare. To prevent bleeding from the IUT procedure to correct anaemia, it is recommended to correct the platelet count as well. In particular, in parvovirus B19 infection $50 \%$ of affected fetuses have thrombocytopenia below $50 \times 10^{\%} / \mathrm{L}$ (range 4-49 × 10\%/L), which further decreases after transfusion of red blood cells (RBC) alone. ${ }^{3,15}$ 
IUPT products are generally obtained by aphaeresis from selected donors. In case of FNAITP, the donors are HPA-1a and/or HPA-5b negative; in case of other antagonisms, washed maternal platelets must be used. Leucocytes are removed from the platelets to prevent CMV transmission and washing removes anti-HPA and other unwanted (maternal) antibodies. After washing, the platelets can be resuspended to the required concentration in AB-citrate plasma, in $\mathrm{NaCl} 0.9 \%$ or in platelet additive solution. For indications other than FNAITP, blood group $\mathrm{O}$, Rh-D-negative donors are mostly selected. To prevent clinically relevant red-cell and leucocyte antibodies eventually causing haemolysis or transfusion-related lung injury, it is advised to limit the donor pool to males without a history of blood transfusion and with a low titre of ABO antibodies. The same donor safety requirements as for IUT with red cells are needed, including CMV and, preferentially, also parvovirus-B19-safe donors, irradiation of the product with 25 Gy to prevent TA-GVHD and a storage interval less than 24-48 hours after withdrawal to provide a long platelet survival. The aim of IUPT is to increase the fetal platelet count above $300 \times 10^{9} / \mathrm{L}$ to ensure a platelet level above $30 \times 10^{9} / \mathrm{L}$ for at least 1 week. This can be achieved by preparing leucocyte-reduced high-concentration platelet products $\left(1-3 \times 10^{11}\right.$ in $50-60 \mathrm{~mL}$ ) by aphaeresis systems. ${ }^{28}$

Platelet transfusions can also be complicated by fetal bradycardia, and, besides haemodynamic causes, soluble factors (e.g. CD40 ligand) in platelet products can play a role. ${ }^{29}$

\section{Neonatal transfusions}

Three categories of patients are at high risk of receiving neonatal transfusions: infants with (allo)immune anaemia and thrombocytopenia, neonates needing extracorporeal membrane oxygenation or surgery and infants born preterm.

\section{Transfusion of red blood cells Exchange and massive transfusions}

Exchange transfusions (ET) are mostly indicated for hyperbilirubinaemia. The bilirubin trigger ranges between 175 and $450 \mu \mathrm{mol} / \mathrm{L}$ and depends on comorbidity, such as pre- or dysmaturity, septicaemia, asphyxia and the speed of bilirubin increase. Polycythaemia and hyperkalaemia are also indications for ET, although evidence for the benefit of this practice is lacking. ${ }^{30} \mathrm{RBC}$ used for ET should be compatible with mother and child, and in general should be O-Rh-D, K negative, leucoreduced, and stored for less than 5 days because of 2,3-biphosphoglycerate levels. According to guidelines, either whole blood from donors lacking high-titre anti-A and anti-B and irregular red-cell antibodies or reconstituted red cells to a $\mathrm{Ht}$ of circa $40 \%$ with $A B$-citrate plasma (fresh frozen plasma) are used. ${ }^{31,32}$ Plasma from male donors 
lacking leucocyte antibodies that may cause transfusion-related lung injury is recommended. ET for premature infants or for neonates after IUT is irradiated with $25 \mathrm{~Gy}$. The exchange volume is $160 \mathrm{~mL} / \mathrm{kg}$. ET blood contains high levels of glucose and sodium, and lacks ionized calcium. The speed of exchange is maximally $2 \mathrm{~mL} / \mathrm{kg}$ per minute and blood pressure, heart rate and breathing must be monitored. ET reduces the platelet count by $50 \%$ and it is advised to maintain the platelet level above $50 \times 10^{9} / \mathrm{L}$, in particular in preterm infants and in the first few days after delivery. After ET, glucose should be controlled for rebound hypoglycaemia. In sick children, ET is associated with considerable (10\%) morbidity. A mortality rate of $0-2 \%$ is reported, mainly as a result of hypocalcaemia and thrombocytopenia. ${ }^{33}$ In case of massive transfusions, such as for extra corporeal membrane oxygenation or surgery for children less than 3 months old, similar product specifications and monitoring as for ET are advised.

\section{Top-up transfusions}

Despite changes in transfusion practices, prematurely born infants, especially extremely and very low birth weight infants, are still heavily transfused.

Blood drawn for laboratory investigation is an important cause of the need for RBC transfusion in these infants, next to erythropoietin (EPO) deficiency and critical illness anaemia. Microanalysis and point-of-care instrumentation, as well as indwelling lines, have reduced the amount of blood needed for testing but a critical approach to every test requested is still necessary. ${ }^{34}$

Over the past two decades, restrictive guidelines and greater awareness have resulted in a $70 \%$ decline in the volume of transfused erythrocytes, as well as $54-80 \%$ reduction in the number of donors to which infants are exposed. . $^{35,36}$

Most neonatal intensive care units use a transfusion protocol based on clinical condition, mechanical ventilation, gestational age, oxygen use and $\mathrm{Ht}$ or haemoglobin $(\mathrm{Hb})$ level. However, with respect to $\mathrm{Hb}$, there is no consensus on appropriate transfusion triggers and the volume of blood to be transfused.

Two randomized controlled studies have recently addressed this question.

In the large multi-centre Premature Infants in Need of Transfusion (PINT) study, more than 450 infants with a birth weight $<1000 \mathrm{~g}$ and a gestational age $<31$ weeks were enrolled within $48 \mathrm{~h}$ of birth. ${ }^{37}$ They were randomly assigned to a high or a low transfusion threshold. The attending physicians were free to give RBC for 'clinical reasons', bypassing the threshold. In all, $89 \%$ of infants in the low-threshold group received RBC versus 95\% in the high-threshold group ( $p=0.037$ ); there was no significant difference in the total amount of transfusions in both groups. Because a single-donor program was not used, the low-threshold group was exposed to significantly fewer donors than the high-threshold group $(p=0.035)$. The compos- 
ite primary outcome (death or survival with major morbidity) and the secondary outcomes - including $\mathrm{Hb}$ levels, transfusion exposure, infections, growth rate, length of oxygen need and hospital stay in both groups - were similar, showing no negative effects when maintaining a lower $\mathrm{Hb}$ level.

A second, single-centre, study by Bell et al. showed an increase in intraparenchymal brain haemorrhage and periventricular leucomalacia in a group with a restrictive transfusion guideline compared with a liberal transfusion guideline; ${ }^{38}$ the lower threshold group also had more apnoea. The number of donors to whom the infants were exposed was not significantly different, although fewer units were given in the restrictive transfusion group than in the liberal transfusion group ( $3.3 \pm 2.9$ versus $5.2 \pm 4.5 ; p=0.025)$.

The unequivocal outcomes of these studies have been discussed extensively. As more liberal transfusion triggers failed to demonstrate deleterious effects, it might be prudent not to use low $\mathrm{Hb} / \mathrm{Ht}$ transfusion triggers unless in clinical studies.

Guidelines need not to be generalized in the first $24 \mathrm{~h}$ after birth. Children born after (prolonged) intrauterine anaemia are accustomed to a lower haemoglobin level and may not need an RBC transfusion. However, newborns with severe intrapartum blood loss will need supplementation to make up for the lost blood and volume; their first $\mathrm{Hb}$ level shortly after birth will not show their true $\mathrm{Hb}$ count.

Table 1 summarizes thresholds for RBC as published in different articles. Nearly all centres take into account the postnatal age and whether a child is on ventilatory support or needs supplemental oxygen.

Although determined by the desired $\mathrm{Hb} / \mathrm{Ht}$ after transfusion, the volume of RBC used for transfusion has not been much studied and varies from 5 to $20 \mathrm{~mL} / \mathrm{kg}$. A study by Paul et al., comparing 10 to $20 \mathrm{~mL} / \mathrm{kg}$ of RBC, showed no negative effects on the pulmonary function with the larger volume. ${ }^{39}$ Wong et al. showed that when giving $20 \mathrm{~mL} / \mathrm{kg}$ instead of $15 \mathrm{~mL} / \mathrm{kg}$, fewer RBC transfusion events were necessary without any negative side effects. ${ }^{40}$ Comparison of transfusion volumes is hampered by the different $\mathrm{Ht}$ of the products used. RBCs suspended in CPD-A usually have an $\mathrm{Ht}$ of around $40 \%$, unless citrate phosphate dextrose adenine (CPD-A) plasma is reduced. In extended-storage media the $\mathrm{Ht}$ is $60 \pm 5 \%$ and in some centres RBCs are centrifuged to a packed RBC concentrate of $80 \% .{ }^{41}$ These differences in $\mathrm{Ht}$ should be taken into account when comparing different transfusion strategies but they are not always clearly mentioned in the reports, and even lacking in randomized studies. ${ }^{35,42}$ RBC used for young infants can be stored without causing negative effects when transfused. Strauss showed that small-volume transfusions $\left(10-20 \mathrm{~mL} / \mathrm{kg}\right.$ ), stored for up to 42 days, ${ }^{41}$ could be used safely. Because a small volume is given, there is hardly any rise in serum potassium or decrease in RBC 2,3-biphosphoglycerate, and the potential negative influence of 


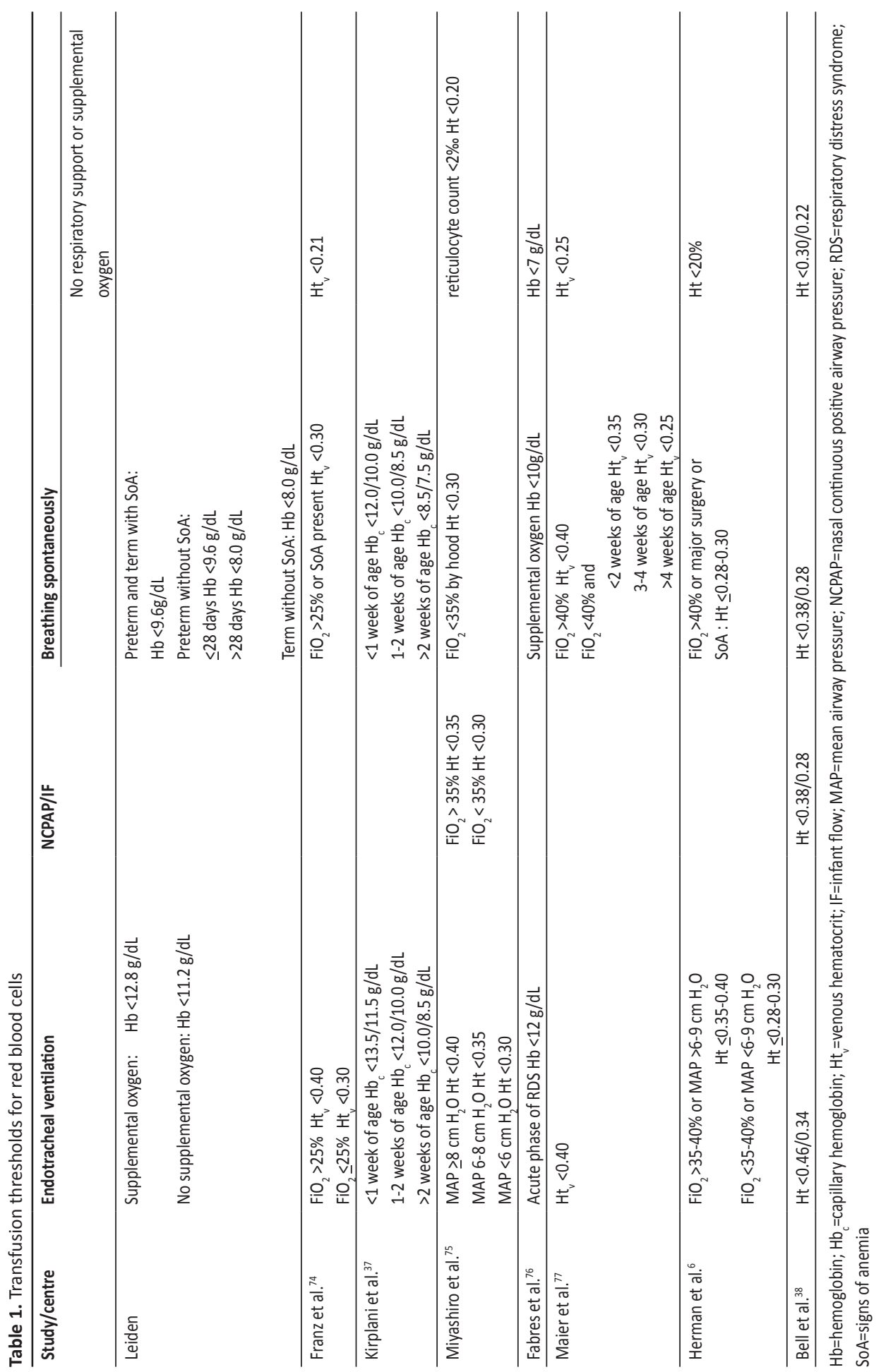


the preservatives can be dismissed. These findings support the use of single-donor unit RBCs for multiple transfusions in extremely and very low birth weight infants. One donor RBC unit is divided into four or five smaller pedipacks, which can be reserved for one (or two) infant(s). The aim of a single-donor program is to expose infants to as few risks of transfusion-acquired infection, and, in particular, infections for which testing is not mandatory, as possible. White blood cell reduction is commonly used to prevent CMV transmission in RBC products as well as in platelet units. Other possible negative effects of white blood cells such as classic non-haemolytic febrile transfusion reactions, are very rare in neonates. Transfusions intended for neonates born before a gestational age of 32 weeks, or for a child who received IUTs, are irradiated with 25 Gy to prevent TA-GVHD. ${ }^{3-6}$

\section{Alternative approaches to reduce red-cell transfusions}

For optimal application of alternative approaches to reduce transfusions, it is important to make a reliable risk estimation for transfusion. In a study by Jansen et al., ${ }^{43}$ gestational age, birth weight and Apgar score at 1 minute were significant predictors for receiving an RBC transfusion in the first 30 days of life. Eighty-nine $\%$ of the infants with a gestational age $<32$ weeks, a birth weight below $1000 \mathrm{~g}$ and almost all infants with this weight and an Apgar score of $<6$ at 1 min needed at least one RBC transfusion.

In a study designed to predict which infants would benefit from erythropoietin, i.e. need an RBC transfusion after the second week of life, gestational age, 5-min Apgar score, transfusion during the first week of life and patent ductus arteriosus ligation were predictive factors for needing at least 2 transfusions. Gestational age $<30$ weeks alone or combined was the best overall predictor. ${ }^{44}$ Alternatives should be sought for this young age group.

\section{Delayed cord blood clamping}

In 2007, Rabe and colleagues performed a systematic review of delayed cord clamping in prematurely born infants; the review was based on ten studies and included a total of 454 infants. ${ }^{45}$ There was a lower transfusion need $(p=0.004)$ and a lower incidence of ICH $(p=0.002)$ in the delayed clamped group than in the early clamped group. Subsequently, Strauss published a randomized controlled trial in 105 neonates between 30 and 36 weeks gestation but found no difference in RBC transfusion needs and clinical outcomes between the groups. Children of $<30$ weeks gestation could not be included because of technical problems - including immediate resuscitation needs - with delayed cord clamping. ${ }^{46}$ 


\section{Autologous cord blood transfusion}

Brune et al. took umbilical cord blood (UCB) from 290 term and premature newborns. ${ }^{47}$ Of this group, 52 infants received an autologous placental blood transfusion; 30 because of anaemia of prematurity (AOP), the others for surgery directly after birth or in the first month of life. The amount of harvested blood was sufficient to cover all transfusion needs in about $40 \%$ of the infants with a birth weight between 1000 and $2500 \mathrm{~g}$; all extremely low birth weight infants $(<1000 \mathrm{~g})$ needed additional allogenic RBC. ${ }^{47}$ Brune et al. concluded that, for term infants requiring surgery in the first few weeks of life, and for premature infants with a birth weight $>1000 \mathrm{~g}$ and a gestational age $<35$ weeks, autologous cord blood can be an alternative source of RBC to allogeneic products. ${ }^{47}$ Several other studies confirmed the use of autologous cord blood for infants requiring surgery for antenatal diagnosed birth defects. In 50-64\% of these mostly term-born infants, the harvested cord blood red cells were sufficient to cover all transfusion needs. ${ }^{48,49}$

Blood processing problems and a bacterial contamination rate of $8.6 \%$ were identified for cord blood transfusion of small premature infants with collected volumes of less than $30 \mathrm{~mL}$. In the small number of children in whom an autologous cord blood red cell transfusion was possible, there was a similar rise in $\mathrm{Hb} / \mathrm{Ht}$ as compared to donor $\mathrm{RBC}$ transfusions. ${ }^{50}$

We performed a double-blind, randomized controlled to assess the feasibility of the use of autologous cord blood for AOP for infants born at a gestational age of $<32$ weeks (unpublished data). Due to low collected volumes, autologous products were available for only $27 \%$ of the infants needing transfusions, replacing $75 \%$ of allogeneic RBC for these children born between a gestational age of 27-30 weeks. Technically, UCB collection and processing are possible, but the costs are high.

\section{Recombinant erythropoietin}

Newborns do not produce EPO for the first two weeks of life and RBC transfusion further depresses the EPO response to anaemia. ${ }^{51}$ Several Cochrane studies have investigated the use of low- or high-dose EPO administered early (within the first week of life) or late (after the first week of life). These studies have evaluated exposure to RBC transfusions, the number of blood donors, clinical complications (retinopathy of prematurity) and hospital stay as endpoints, but have found no evidence for the use of EPO. ${ }^{52}$

\section{Platelet transfusion}

A thrombocyte count below $150 \times 10^{9} / \mathrm{L}$ in newborn infants is pathologic. The risk of severe thrombocytopenia $\left(<50 \times 10^{9} / \mathrm{L}\right)$ is haemorrhage, specifically an ICH with the danger of severe 
neurological damage or death. ${ }^{53-56}$ To correct an abnormal platelet count, the cause of the thrombocytopenia should be taken into account.

Causes include maternal pathology such as HELLP (hypertension, elevated liver enzymes, low platelets) syndrome or (pre-)eclampsia with placental insufficiency, maternal idiopathic thrombocytopenia, fetal or neonatal alloimmune thrombocytopenia (FNAITP), sepsis, drugs and diffuse intra vascular coagulation. Whereas early thrombocytopenia often has a maternal reason, late thrombocytopenia - developing 3 days after birth or later - generally has a nosocomial cause. Newborns who receive platelets to treat thrombocytopenia have a higher mortality rate than neonates with a normal platelet count. The severity of the underlying disease explains the higher probability of death; thrombocytopenia and bleeding is not the cause of excess death rates. ${ }^{55,57,58}$

In cases of platelet transfusions it is important to distinguish between alloimmune thrombocytopenia and other causes; first, because newborns with FNAITP, irrespective of prematurity, have a high risk for massive $\mathrm{ICH}$; and second, because HPA-compatible platelets are warranted. The frequency of FNAITP in Caucasian populations is 1:1200 newborns. Prompt transfusion with HPA-1a-negative or HPA-5b-negative platelets is effective in $85-95 \%$ of cases. ${ }^{59}$ Transfusion is generally undertaken during a planned delivery in women treated antenatally with IVIG. Often, just one HPA-matched transfusion is sufficient to maintain a stable platelet count above $100 \times 10^{9} /$ L. $^{60}$ However, in $50 \%$ of the cases in which NAITP presents unexpectedly in a firstborn, HPA-compatible platelets might not be available and production and testing of washed (to remove antibodies) maternal platelets will cause a delay of 12-24 h. In a retrospective study in 27 newborns with FNAITP, Kiefel and colleagues observed a moderate to good increment in 24 children after random platelet transfusions and, moreover, no adverse effects. ${ }^{61}$ Random platelet transfusions can thus be used, awaiting matched platelets or effect of other therapy (i.e. IVIG), although the benefits of concomitant IVIG have not yet been shown. ${ }^{60,61}$

Another maternal cause of neonatal thrombocytopenia is idiopathic thrombocytopenia. The occurrence of $\mathrm{ICH}$ during and after delivery is estimated 0-1.5\%, and prompt random platelet transfusions, in conjunction with corticosteroids or IVIG, are indicated in case of severe bleeding. ${ }^{27}$ Neonatal thrombocytopenia associated with maternal eclampsia and HELLP resolves spontaneously the first week after birth and needs no treatment. ${ }^{60}$

A study by Bonifacio et al. found that two-thirds of the cases of severe thrombocytopenia $\left(<50 \times 10^{9} / L\right)$ occurred beyond 72 hours after birth in a group of very prematurely born infants with a gestational age $<30$ weeks. ${ }^{62}$ No correlation was found between the severity or the time of onset of the thrombocytopenia and the occurrence of ICH. Platelets were administered in $85 \%$ of the cases of severe thrombocytopenia and in $65 \%$ of the moderate cases (platelet 
count 50-100 $\times 10^{9} /$ L) without a reduction in mortality in the transfused group compared to the non-transfused group.

Murray et al. conducted a retrospective study in their own neonatal intensive care unit, evaluating all patients with a platelet count $<50 \times 10^{9} / \mathrm{L}$ over a three-year period. ${ }^{58}$ Six percent of the admissions developed a severe thrombocytopenia, most often after the first few days of life, thus after the critical period for developing severe $\mathrm{ICH}$.

A randomized controlled trial conducted by Andrew et al. compared no-treatment for a platelet count between 50 and $150 \times 10^{9} / \mathrm{L}$ with prophylactic platelet transfusion. They found a comparable short-term neonatal outcome irrespective of the child's clinical condition at time of thrombocytopenia. ${ }^{53}$

The trigger for platelet transfusions varies among guidelines. Most neonatal units use a protocol taking platelet count, disease severity, indwelling drains, artificial ventilation or any recent surgery into account. Table 2 summarizes various protocols to show that - except in cases of major bleeding, $\mathrm{ICH}$ and surgery (for which a trigger of $100 \times 10^{9} / \mathrm{L}$ is recommended) - most centres consider platelet transfusions in infants in whom the platelet count is $<50 \mathrm{x}$ $10^{\%} / \mathrm{L}$; in stable infants an even lower platelet count can also be considered. ${ }^{5,55,63}$ The different protocols also stress the importance of aggressive treatment of the underlying condition causing the thrombocytopenia. As stated by Calhoun et al., guidelines are based on consensus of practice, and not meant to be strict rules. Rather, they should be seen as aids to making decisions in one's own practice. ${ }^{63}$

There are no studies to recommend whether thrombocytes should be given as a concentrate or as a suspension. Concentration of platelets causes approximately $15 \%$ platelet loss and, once in a syringe, the shelf life is reduced to a maximum of $6 \mathrm{~h} .{ }^{64}$ Currently, aphaeresis devices can collect such highly concentrated platelets, which can be stored for $1-3$ days. ${ }^{28}$ Calhoun et al. advise giving 10-15 mL/kg CMV-negative standard platelet suspension (containing circa $1 \mathrm{x}$ $10^{9}$ platelets $/ \mathrm{mL}$ ), which should raise the platelet count by approximately $100 \times 10^{9} / \mathrm{L}^{63}$ In our centre, we transfuse platelet concentrates of $5 \mathrm{~mL}$ derived from a single donor (containing circa $10 \times 10^{9}$ platelets $/ \mathrm{mL}$ ) and transfuse $10 \times 10^{9}$ thrombocytes $/ 500 \mathrm{~g}$ infant weight (up to 2500 grams, above which we use $10 \mathrm{~mL}$ ).

Platelet transfusions are not without risks; these include bacterial contamination, transmission of viral agents and transfusion-related lung injury. ${ }^{55,65}$ Consequently, adequate indication, the best product and quantity of platelet products and alternative treatments should be investigated. Even when we put the infants at risk for haemorrhage, without randomized controlled trials we will never know the safe thresholds for transfusion. 
Table 2. Thrombocyte transfusion triggers

\begin{tabular}{|c|c|c|c|c|}
\hline Study & $\begin{array}{l}\text { Trigger } \\
\text { stable }\end{array}$ & $\begin{array}{c}\text { Trigger } \\
\text { unstable }\end{array}$ & Definition unstable & No transfusions \\
\hline Calhoun et al ${ }^{63}$ & $<25$ & 50 & $\begin{array}{l}\text { surgery or within } 5 \text { days after surgery, cardiovascular instability, } \\
\text { respiratory instability, }<72 \text { hours after seizure, DIC, }<1500 \text { gram } \\
\text { and }<7 \text { days }\end{array}$ & \\
\hline Roberts et al..$^{55}$ & $<30$ & $30-49$ & consider if $<1000$ gram and $<7$ days, bleeding, clinically & \\
\hline \multirow[t]{5}{*}{ Murray et al. ${ }^{74}$} & & & unstable, previous major bleed (IVH 3-4 or pulmonary & \\
\hline & & & bleeding), current minor bleeding (petechiae, oozing from & \\
\hline & & & puncture sites, stained endotracheal secretions), current & \\
\hline & & & coagulopathy, necessary surgery or exchange transfusion & \\
\hline & & $50-99$ & if bleeding & $>100$ \\
\hline \multirow[t]{2}{*}{ Leiden } & $<30$ & $30-49$ & $\begin{array}{l}\text { if }<1000 \text { grams and }<1 \text { week, previous major bleeding, } \\
\text { exchange transfusion, planned surgery, platelet count expected } \\
\text { to drop below } 30\end{array}$ & \\
\hline & & $50-100$ & if bleeding & $>100$ \\
\hline
\end{tabular}

Numbers are platelet counts $\times 10^{9} / \mathrm{L}$, unless otherwise stated

$\mathrm{DIC}=$ diffuse intravascular coagulation; IVH=intraventricular haemorrhage

\section{Alternative approaches to thrombocyte transfusions}

Virtually no alternatives exist for bleeding neonates with thrombocytopenia. ${ }^{55}$ IVIG, corticosteroids and thrombopoietin do not increase the platelet count instantly, and results with recombinant factor VIla, used in children and adults, are lacking in neonates.

\section{Granulocyte transfusion}

The most common causes of leucocytopenia in the neonatal intensive care unit are sepsis, maternal hypertension, and endotoxemia. ${ }^{66}$ Alloimmune maternal antibodies are a very rare cause of neonatal neutropenia. Neutropenia associated with maternal hypertension resolves spontaneously within hours to days and needs no treatment.

Septic newborns with granulocytopenia have a higher mortality rate than infants with a normal or raised white blood cell count upon infection. ${ }^{67}$ Neutrophil transfusions are not useful in the prevention of infections but can be administered to help clear infections in infants with severe neutropenia being treated with antibiotics. ${ }^{68}$ Granulocyte transfusions are used infrequently in neonatal sepsis ${ }^{66}$ and there are no evidencebased studies on the use of granulocytes in newborns. A dose of $1-2 \times 10^{10} / \mathrm{L}$ granulocytes per $\mathrm{kg}$ is suggested for effective treatment and this must be repeated daily or on alternative days for 1-2 weeks. ${ }^{69}$ Granulocytes can be prepared on demand from (pooled, blood group O-Rh-D negative) buffy coats, but these contain fewer neutrophils than granulocytes obtained by aphaeresis of G-CSF stimulated donors and, in adults, are less effective in reducing mortality. ${ }^{70}$ 
It is possible that the infusion of buffy coat granulocytes has more side effects than granulocyte colony stimulating factor (GCS-F) mobilized aphaeresis leucocytes. Wheeler et al. treated four infants with buffy coat granulocytes. In 2 infants the respiratory problems worsened after the infusion, possibly due to leucoagglutination, as described in adults. ${ }^{71}$ In a study by Baley et al. two of 13 infants had a decrease in $\mathrm{P}_{\mathrm{a}} \mathrm{O} 2$ of more than $30 \mathrm{mmHg}$ during their third granulocyte transfusion. This resolved spontaneously but no more leucocyte transfusions were given to these children. ${ }^{72}$

A Cochrane review on the effect of granulocyte transfusion in septic, neutropenic infants being treated with antibiotics compared to placebo or no transfusion showed no significant difference in all cause mortality. Compared with IVIG, there was a borderline statistical difference in favour of the granulocyte transfusion in a study with 35 neonates. No long-term outcome was reported. ${ }^{73}$

In leucocytopenia caused by maternal antibodies, G-CSF should attain a quicker response than IVIG. ${ }^{66}$

Multi-centre, randomized controlled studies are necessary to achieve adequate power and sufficient patients enrolled in an acceptable time span, to be able to conclude on the effect of granulocyte transfusions.

\section{Practice points}

- Intrauterine RBC transfusions induce additional maternal erythrocyte antibodies in $25 \%$, therefore compatibility tests must be performed with fresh maternal serum before every transfusion.

- $\quad$ RBC used for IUT should be manipulated as little as possible and there should be a short interval between processing/irradiation and transfusion because of potassium load.

- Intrauterine platelet transfusion is controversial and the high risk of transfusion-related complications must be balanced against the risk of $\mathrm{ICH}$.

- The first-line treatment for intrauterine alloimmune thrombocytopenia is maternal IVIG.

- Delayed cord clamping should be considered for very low birth-weight infants if clinical condition permits.

- HPA-1a-negative and HPA-5b-negative donor platelets should always be available for neonates known with NAITP.

- For neonates suspected for FNAITP, random platelets are not contra-indicated while awaiting compatible (maternal) platelets. 
- A critical approach to blood taking for investigation, next to alternatives to donor RBC, could reduce the number of allogenic transfusions to neonates, especially in those born $<30$ weeks gestation.

\section{Research agenda}

- Clinical studies on appropriate transfusion thresholds, volumes and products.

- Identification of patients who can benefit most from alternatives to allogeneic RBC transfusions.

- Prophylactic platelet transfusion studies using bleeding as the endpoint.

- Multicentre collaborative studies into the safety and efficacy of granulocyte transfusions.

- To improve care without taking risks, a study by an international consortium should compare differences in transfusion policy. 


\section{Reference List}

1. van Kamp I, Klumper FJ, Oepkes D, Meerman RH, Scherjon SA, Vandenbussche FP et al. Complications of intrauterine intravascular transfusion for fetal anemia due to maternal red-cell alloimmunization. Am J Obstet Gynecol 2005; 192(1):171-177.

2. Birchall JE, Murphy MF, Kaplan C, Kroll H. European collaborative study of the antenatal management of feto-maternal alloimmune thrombocytopenia. Br J Haematol 2003; 122(2):275-288.

3. de Haan TR, van den Akker ES, Porcelijn L, Oepkes D, Kroes AC, Walther FJ. Thrombocytopenia in hydropic fetuses with parvovirus B19 infection: incidence, treatment and correlation with fetal B19 viral load. BJOG 2008; 115(1):76-81.

4. Kwaliteitsinstituut voor Gezondheidszorg CBO. Richtlijn bloedtransfusie. 2004.

5. Gibson BE, Todd A, Roberts I, Pamphilon D, Rodeck C, Bolton-Maggs P et al. Transfusion guidelines for neonates and older children. Br J Haematol 2004; 124(4):433-453.

6. Herman JH, Manno CS. Pediatric Transfusion Therapy. 2003. AABB press.

7. Hoch J, Giers G, Bald R, Hansmann M, Hanfland P. [Antibody induction after intrauterine interventions]. Infusionsther Transfusionsmed 1993; 20 Suppl 2:70-73.

8. Schonewille $\mathrm{H}$, Klumper FJ, van de Watering LM, Kanhai $\mathrm{HH}$, Brand A. High additional maternal red cell alloimmunization after Rhesus- and K-matched intrauterine intravascular transfusions for hemolytic disease of the fetus. Am J Obstet Gynecol 2007; 196(2):143-146.

9. Arseniev L, Schumann G, Andres J. Kinetics of extracellular potassium concentration in irradiated red blood cells. Infusionsther Transfusionsmed 1994; 21(5):322-324.

10. Galligan BR, Cairns R, Schifano JV, Selbing A, Bernvil SS. Preparation of packed red cells suitable for intravascular transfusion in utero. Transfusion 1989; 29(2):179-181.

11. Gonsoulin WJ, Moise KJ, Jr., Milam JD, Sala JD, Weber VW, Carpenter RJ, Jr. Serial maternal blood donations for intrauterine transfusion. Obstet Gynecol 1990; 75(2):158-162.

12. el-Azeem SA, Samuels P, Rose RL, Kennedy M, O'Shaughnessy RW. The effect of the source of transfused blood on the rate of consumption of transfused red blood cells in pregnancies affected by red blood cell alloimmunization. Am J Obstet Gynecol 1997; 177(4):753-757.

13. Giannina G, Moise KJ, Jr., Dorman K. A simple method to estimate volume for fetal intravascular transfusions. Fetal Diagn Ther 1998; 13(2):94-97.

14. Rodeck CH, Nicolaides KH, Warsof SL, Fysh WJ, Gamsu HR, Kemp JR. The management of severe rhesus isoimmunization by fetoscopic intravascular transfusions. Am J Obstet Gynecol 1984; 150(6):769-774.

15. Vietor HE, Klumper F, Meerman RJ, Brand A, Kanhai HH. Intrauterine transfusions influence fetal leukocyte counts and subsets. Prenat Diagn 1998; 18(4):325-331.

16. Lasker MR, Eddleman K, Toor AH. Neonatal hepatitis and excessive hepatic iron deposition following intrauterine blood transfusion. Am J Perinatol 1995; 12(1):14-17.

17. Saade GR, Moise KJ, Jr., Copel JA, Belfort MA, Carpenter RJ, Jr. Fetal platelet counts correlate with the severity of the anemia in red-cell alloimmunization. Obstet Gynecol 1993; 82(6):987-991.

18. Segal M, Manning FA, Harman CR, Menticoglou S. Bleeding after intravascular transfusion: experimental and clinical observations. Am J Obstet Gynecol 1991; 165(5 Pt 1):1414-1418.

19. Mueller-Eckhardt C, Kiefel V, Grubert A, Kroll H, Weisheit M, Schmidt S et al. 348 cases of suspected neonatal alloimmune thrombocytopenia. Lancet 1989; 1(8634):363-366.

20. Feng ML, Liu DZ, Shen W, Wang JL, Guo ZH, Zhang X et al. Establishment of an HPA-1- to -16-typed platelet donor registry in China. Transfus Med 2006; 16(5):369-374. 
21. King KE, Kao KJ, Bray PF, Casella JF, Blakemore K, Callan NA et al. The role of HLA antibodies in neonatal thrombocytopenia: a prospective study. Tissue Antigens 1996; 47(3):206-211.

22. Williamson LM, Hackett G, Rennie J, Palmer CR, Maciver C, Hadfield R et al. The natural history of fetomaternal alloimmunization to the platelet-specific antigen HPA-1a (PIA1, Zwa) as determined by antenatal screening. Blood 1998; 92(7):2280-2287.

23. Bussel JB, Berkowitz RL, McFarland JG, Lynch L, Chitkara U. Antenatal treatment of neonatal alloimmune thrombocytopenia. N Engl J Med 1988; 319(21):1374-1378.

24. Radder CM, Brand A, Kanhai HH. Will it ever be possible to balance the risk of intracranial haemorrhage in fetal or neonatal alloimmune thrombocytopenia against the risk of treatment strategies to prevent it? Vox Sang 2003; 84(4):318-325.

25. Kanhai $\mathrm{HH}$, van den Akker ES, Walther FJ, Brand A. Intravenous immunoglobulins without initial and follow-up cordocentesis in alloimmune fetal and neonatal thrombocytopenia at high risk for intracranial hemorrhage. Fetal Diagn Ther 2006; 21(1):55-60.

26. Ghevaert C, Campbell K, Walton J, Smith GA, Allen D, Williamson LM et al. Management and outcome of 200 cases of fetomaternal alloimmune thrombocytopenia. Transfusion 2007; 47(5):901-910.

27. Guidelines for the investigation and management of idiopathic thrombocytopenic purpura in adults, children and in pregnancy. Br J Haematol 2003; 120(4):574-596.

28. Dumont LJ, Krailadsiri P, Seghatchian J, Taylor LA, Howell CA, Murphy MF. Preparation and storage characteristics of white cell-reduced high-concentration platelet concentrates collected by anapheresis system for transfusions in utero. Transfusion 2000; 40(1):91-100.

29 Yazicioglu HF, Hartwig D, von Witzleben-Schurholz E, Neppert J, Gembruch U. Fetal bradycardia following intrauterine platelet transfusion: might elevated levels of donor soluble CD40 ligand play a role? Acta Obstet Gynecol Scand 2004; 83(9):868-869.

30. Rosenkrantz TS. Polycythemia and hyperviscosity in the newborn. Semin Thromb Hemost 2003; 29(5):515527.

31. Guidelines for the use of platelet transfusions. Br J Haematol 2003; 122(1):10-23.

32. Stern SC, Cockburn H, de Silva PM. Current practice in neonatal exchange transfusions: a retrospective audit based at one transfusion centre. Transfus Med 1998; 8(2):97-101.

33. Jackson JC. Adverse events associated with exchange transfusion in healthy and ill newborns. Pediatrics 1997; 99(5):E7.

34. Luban NL. Neonatal red blood cell transfusions. Vox Sang 2004; 87 Suppl 2:184-188.

35. Maier RF, Sonntag J, Walka MM, Liu G, Metze BC, Obladen M. Changing practices of red blood cell transfusions in infants with birth weights less than $1000 \mathrm{~g}$. J Pediatr 2000; 136(2):220-224.

36. Widness JA, Seward VJ, Kromer IJ, Burmeister LF, Bell EF, Strauss RG. Changing patterns of red blood cell transfusion in very low birth weight infants. J Pediatr 1996; 129(5):680-687.

37. Kirpalani H, Whyte RK, Andersen C, Asztalos EV, Heddle N, Blajchman MA et al. The Premature Infants in Need of Transfusion (PINT) study: a randomized, controlled trial of a restrictive (low) versus liberal (high) transfusion threshold for extremely low birth weight infants. J Pediatr 2006; 149(3):301-307.

38. Bell EF, Strauss RG, Widness JA, Mahoney LT, Mock DM, Seward VJ et al. Randomized trial of liberal versus restrictive guidelines for red blood cell transfusion in preterm infants. Pediatrics 2005; 115(6):1685-1691.

39. Paul DA, Leef KH, Locke RG, Stefano JL. Transfusion volume in infants with very low birth weight: a randomized trial of 10 versus $20 \mathrm{ml} / \mathrm{kg}$. J Pediatr Hematol Oncol 2002; 24(1):43-46.

40. Wong H, Connelly R, Day A, Flavin MP. A comparison of high and standard blood transfusion volumes in premature infants. Acta Paediatr 2005; 94(5):624-625.

41. Strauss RG. Data-driven blood banking practices for neonatal RBC transfusions. Transfusion 2000; 40(12):1528-1540. 
42. Widness JA, Seward VJ, Kromer IJ, Burmeister LF, Bell EF, Strauss RG. Changing patterns of red blood cell transfusion in very low birth weight infants. J Pediatr 1996; 129(5):680-687.

43. Jansen M, Brand A, Von Lindern JS, Scherjon S, Walther FJ. Potential use of autologous umbilical cord blood red blood cells for early transfusion needs of premature infants. Transfusion 2006; 46(6):1049-1056.

44. Brown MS, Berman ER, Luckey D. Prediction of the need for transfusion during anemia of prematurity. J Pediatr 1990; 116(5):773-778.

45. Rabe H, Reynolds G, az-Rossello J. A Systematic Review and Meta-Analysis of a Brief Delay in Clamping the Umbilical Cord of Preterm Infants. Neonatology 2007; 93(2):138-144.

46. Strauss RG, Mock DM, Johnson KJ, Cress GA, Burmeister LF, Zimmerman MB et al. A randomized clinical trial comparing immediate versus delayed clamping of the umbilical cord in preterm infants: short-term clinical and laboratory endpoints. Transfusion 2008;48(4):658-65

47. Brune T, Garritsen H, Witteler R, Schlake A, Wullenweber J, Louwen F et al. Autologous placental blood transfusion for the therapy of anaemic neonates. Biol Neonate 2002; 81(4):236-243.

48. Imura K, Kawahara H, Kitayama Y, Yoneda A, Yagi M, Suehara N. Usefulness of cord-blood harvesting for autologous transfusion in surgical newborns with antenatal diagnosis of congenital anomalies. J Pediatr Surg 2001; 36(6):851-854.

49. Taguchi T, Suita S, Nakamura M, Yamanouchi T, Ogita K, Taguchi S et al. The efficacy of autologous cordblood transfusions in neonatal surgical patients. J Pediatr Surg 2003; 38(4):604-607.

50. Eichler H, Schaible T, Richter E, Zieger W, Voller K, Leveringhaus A et al. Cord blood as a source of autologous RBCs for transfusion to preterm infants. Transfusion 2000; 40(9):1111-1117.

51. Keyes WG, Donohue PK, Spivak JL, Jones MD, Jr., Oski FA. Assessing the need for transfusion of premature infants and role of hematocrit, clinical signs, and erythropoietin level. Pediatrics 1989; 84(3):412-417.

52. Cochrane. Cochrane Database Syst Rev 2003;CD004863,CD004865,CD004868.

53. Andrew M, Castle V, Saigal S, Carter C, Kelton JG. Clinical impact of neonatal thrombocytopenia. J Pediatr 1987; 110(3):457-464.

54. Castle V, Andrew M, Kelton J, Giron D, Johnston M, Carter C. Frequency and mechanism of neonatal thrombocytopenia. J Pediatr 1986; 108(5 Pt 1):749-755.

55. Roberts I, Murray NA. Neonatal thrombocytopenia: causes and management. Arch Dis Child Fetal Neonatal Ed 2003; 88(5):F359-F364.

56. Van de Bor M, Briet E, Van Bel F, Ruys JH. Hemostasis and periventricular-intraventricular hemorrhage of the newborn. Am J Dis Child 1986; 140(11):1131-1134.

57. Garcia MG, Duenas E, Sola MC, Hutson AD, Theriaque D, Christensen RD. Epidemiologic and outcome studies of patients who received platelet transfusions in the neonatal intensive care unit. J Perinatol 2001; 21(7):415-420.

58. Murray NA, Howarth LJ, McCloy MP, Letsky EA, Roberts IA. Platelet transfusion in the management of severe thrombocytopenia in neonatal intensive care unit patients. Transfus Med 2002; 12(1):35-41.

59. Blanchette VS, Johnson J, Rand M. The management of alloimmune neonatal thrombocytopenia. Baillieres Best Pract Res Clin Haematol 2000; 13(3):365-390.

60. Te Pas AB, Lopriore E, van den Akker ES, Oepkes D, Kanhai HH, Brand A et al. Postnatal management of fetal and neonatal alloimmune thrombocytopenia: the role of matched platelet transfusion and IVIG. Eur J Pediatr 2007; 166(10):1057-1063.

61. Kiefel V, Bassler D, Kroll H, Paes B, Giers G, Ditomasso J et al. Antigen-positive platelet transfusion in neonatal alloimmune thrombocytopenia (NAIT). Blood 2006; 107(9):3761-3763.

62. Bonifacio L, Petrova A, Nanjundaswamy S, Mehta R. Thrombocytopenia related neonatal outcome in preterms. Indian J Pediatr 2007; 74(3):269-274. 
63. Calhoun DA, Christensen RD, Edstrom CS, Juul SE, Ohls RK, Schibler KR et al. Consistent approaches to procedures and practices in neonatal hematology. Clin Perinatol 2000; 27(3):733-753.

64. Pisciotto PT, Snyder EL, Snyder JA, Frattaroli S, Hopfer SM, Rinder HM et al. In vitro characteristics of white cell-reduced single-unit platelet concentrates stored in syringes. Transfusion 1994; 34(5):407-411.

65. Blajchman MA, Goldman M. Bacterial contamination of platelet concentrates: incidence, significance, and prevention. Semin Hematol 2001; 38(4 Suppl 11):20-26.

66. Christensen RD, Calhoun DA, Rimsza LM. A practical approach to evaluating and treating neutropenia in the neonatal intensive care unit. Clin Perinatol 2000; 27(3):577-601.

67. Rodwell RL, Taylor KM, Tudehope DI, Gray PH. Hematologic scoring system in early diagnosis of sepsis in neutropenic newborns. Pediatr Infect Dis J 1993; 12(5):372-376.

68. Vamvakas EC, Pineda AA. Determinants of the efficacy of prophylactic granulocyte transfusions: a metaanalysis. J Clin Apher 1997; 12(2):74-81.

69. Engelfriet CP, Reesink HW, Klein HG, Murphy MF, Pamphilon D, Devereux S et al. International forum: granulocyte transfusions. Vox Sang 2000; 79(1):59-66.

70. Reiss RF, Pindyck J, Waldman AA, Raju M, Kulpa J. Transfusion of granulocyte rich buffy coats to neutropenic patients. Med Pediatr Oncol 1982; 10(5):447-454.

71. Wheeler JG, Chauvenet AR, Johnson CA, Block SM, Dillard R, Abramson JS. Buffy coat transfusions in neonates with sepsis and neutrophil storage pool depletion. Pediatrics 1987; 79(3):422-425.

72. Baley JE, Stork EK, Warkentin PI, Shurin SB. Buffy coat transfusions in neutropenic neonates with presumed sepsis: a prospective, randomized trial. Pediatrics 1987; 80(5):712-720.

73. Mohan P, Brocklehurst P. Granulocyte transfusions for neonates with confirmed or suspected sepsis and neutropaenia. Cochrane Database Syst Rev 2003;(4):CD003956.

74. Franz AR, Pohlandt F. Red blood cell transfusions in very and extremely low birthweight infants under restrictive transfusion guidelines: is exogenous erythropoietin necessary? Arch Dis Child Fetal Neonatal Ed 2001; 84(2):F96-F100.

75. Miyashiro AM, Santos N, Guinsburg R, Kopelman BI, Peres CA, Taga MF et al. Strict red blood cell transfusion guideline reduces the need for transfusions in very-low-birthweight infants in the first 4 weeks of life: a multicentre trial. Vox Sang 2005; 88(2):107-113.

76. Fabres J, Wehrli G, Marques MB, Phillips V, Dimmitt RA, Westfall AO et al. Estimating blood needs for very-low-birth-weight infants. Transfusion 2006; 46(11):1915-1920.

77. Maier RF, Obladen M, Kattner E, Natzschka J, Messer J, Regazzoni BM et al. High-versus low-dose erythropoietin in extremely low birth weight infants. The European Multicenter rhEPO Study Group. J Pediatr 1998; 132(5):866-870.

78. Murray NA, Roberts IA. Neonatal transfusion practice. Arch Dis Child Fetal Neonatal Ed 2004; 89(2):F101F107. 